\title{
La correspondencia de Ricardo Palma en la Biblioteca Nacional del Perú
}

\author{
Carlos Alberto Pérez Garay \\ Universidad Ricardo Palma \\ charlyx333@hotmail.com \\ Lima-Perú
}

\section{Resumen}

El presente trabajo de investigación describe y analiza la vasta correspondencia que tuvo el escritor limeño con diversos personajes del ámbito político, económico, social y cultural del Perú y del mundo, pertenecientes a la Colección Ricardo Palma de la Biblioteca Nacional del Perú.

Palabras Claves: Ricardo Palma, Correspondencia, Biblioteca Nacional

Abstract

This research paper describes and analyzes the vast correspondence that the Lima writer had with various characters from the political, economic, social and cultural spheres of Peru and the world, belonging to the Ricardo Palma Collection of the National Library of Peru.

Keywords: Ricardo Palma, Correspondence, National Library 
Carlos Pérez Garay (Perú): Licenciado en Historia por la Universidad Nacional Mayor de San Marcos. Con estudios de maestría en dicha casa de estudios. Docente e investigador. Ha participado como ponente y conferencista en importantes eventos académicos en el país. Ejerce la docencia en la Universidad Ricardo Palma, en el Programa de Estudios Básicos (PEB) y en la Facultad de Ciencias Económicas y Empresariales. Es especialista en temas de historia política, intelectual y literaria. Sus trabajos aparecen en numerosos artículos de revistas especializadas y en un libro sobre el tradicionalista: Liberalismo criollo, Ricardo Palma, ideología y política (1833-1919), publicado en Lima, en 2015, por el Fondo editorial de la Universidad Ricardo Palma. 


\section{Introducción}

En 1949, por medio de la Resolución Ministerial № 1439, la Biblioteca Nacional del Perú adquirió en la suma de cincuenta mil soles de oro $(\mathrm{S} / 50.000 .00)$, a la señorita doña Augusta Palma, la biblioteca personal de su padre, el insigne literato don Ricardo Palma, constante de un millar de volúmenes; su archivo personal formado por veintiséis tomos de correspondencia en donde figuran cartas y autógrafos de los más eminentes escritores, diplomáticos y hombres de estado del mundo, e infinidad de documentos del más subido valor e interés; y también numerosos recuerdos personales del autor de las Tradiciones Peruanas. Entre estos recuerdos figuran retratos, álbumes, diplomas, condecoraciones y otros objetos. Con estos elementos se pretendía constituir en la Biblioteca Nacional un museo de nombre Ricardo Palma, como homenaje al insigne director que, después de haberla reconstruido, presidió durante más de un cuarto de siglo su marcha, habiendo llegado a identificarse profundamente con ella.

Efectuada la compra, el archivo y la biblioteca del tradicionista fueron trasladados a la sede central de la Biblioteca Nacional, en la avenida Abancay, estando bajo el cuidado del Departamento de Investigaciones Bibliográficas, creado en 1948 durante la gestión del ingeniero Cristóbal Losada y Puga.

Por sus relaciones con las más destacadas personalidades de su época, la biblioteca personal y el archivo del eximio literato contienen materiales preciosos que pueden ser aprovechados ventajosamente por los investigadores del Perú y del extranjero.

\section{Historia de esta colección}

A lo largo de su vida, el escritor limeño don Ricardo Palma mantuvo una intensa correspondencia epistolar con varias 
personalidades peruanas y extranjeras del ámbito académico, político e intelectual. Sus inicios en la actividad epistolar pueden remontarse a su época de adolescente, cuando cursaba estudios en el Colegio particular del italiano Antonio de Orengo y luego en el Convictorio de San Carlos, allá por la década de 1840. Al incursionar en la actividad literaria y periodística, su actividad epistolar empezó a incrementarse, por lo que acudir al correo para dejar una carta o llegar a casa para recibir al cartero fuera tal vez rutina propia del joven mozalbete. Al ingresar a la Marina en 1853, el hábito de escribir y recibir cartas se hizo más frecuente. Desde los diversos lugares del litoral peruano que logró recorrer, Palma no dejó de escribir misivas a sus amigos y familiares de la capital.

Habría que indicar también que aunque originalmente el rasgo principal de las cartas era ser estrictamente privadas, el escritor no pudo evitar escribir, como muchos de sus amigos de generación, algunas cartas públicas, las cuales enviaba a las oficinas de redacción de algunos tabloides limeños. En efecto, son muy conocidas, en la década de 1850, sus cartas públicas dirigidas al maestro italiano José Musso, dueño de la casa en que vivía con su padre, y al pintor Francisco Laso, autor del "Aguinaldo para las señoras del Perú", las que fueron reproducidas en las páginas de El Comercio y El Heraldo de Lima.

No obstante, por sus múltiples ocupaciones en la Armada, parece muy poco probable que durante esta década se haya dedicado a coleccionar las cartas que sus amigos le dirigían. Al parecer, la afición por el cuidado de su correspondencia personal pudo haber empezado durante el tiempo que residió en Chile, país al que viajó luego de estar involucrado en una intentona golpista en 1860 (Holguín, 1994, p. 641). Desde el país sureño, Palma logró intercambiar correspondencia con varios de sus amigos chilenos como Diego Barros Arana, Guillermo Matta, Miguel Luis Amunátegui, Benjamín Vicuña Mackenna y Alberto Blest 
Gana. La misma correspondencia epistolar lo hizo también con algunos de sus compatriotas residentes en Lima. Uno de ellos fue el médico José Casimiro Ulloa, su compañero de aventura literaria, redactor de La Revista de Lima e integrante del Partido Liberal con quien mantuvo una activa correspondencia entre 1861 a 1862. (Palma, 2005, pp. 39-58).

Al retornar a Lima en octubre de 1862, el escritor limeño pudo traer algunas de las cartas de su estadía chilena, las cuales debió de guardar con profundo cariño. $\mathrm{Al}$ año siguiente, Palma siguió manteniendo una variada correspondencia epistolar con varios de sus colegas peruanos y del extranjero. Una de las cartas más recordadas es la que le envió, el 15 de noviembre de 1863 desde París, el escritor colombiano, José María Torres Caicedo, a quien llegó a conocer en 1865 en la capital francesa (Holguín, 2000). En suelo francés, y en los otros países europeos que recorrió, Palma no llegó a escribir muchas cartas, ello recién ocurriría con frecuencia en 1866, un año después de su llegada al Perú (Palma, 2005, I, p. 87). En 1868, el coronel José Balta es elegido presidente del Perú. Al asumir el cargo nombró como secretario de su despacho a su amigo Ricardo Palma, quien lo acompañó durante toda su gestión. Como secretario privado de Balta, Palma realizó muchas actividades (Pérez Garay, 2015, pp. 196-197). Una de ellas fue ocuparse de la correspondencia del Jefe de Estado. Autorizado por éste, el escritor leyó y respondió una considerable cantidad de misivas de diversos lugares del país y del extranjero que llegaba al despacho presidencial. Así se convertió en un corresponsal nato. Palma estuvo a cargo de la correspondencia de Balta hasta el fatídico lunes 22 de julio de 1822, día en que se produjo el alzamiento de los hermanos Gutiérrez. Aquella mañana, el escritor logró escapar de Palacio llevando parte de la correspondencia privada del Presidente. Según cuenta el tradicionista: "Cuando la malvada revolución de los Gutiérrez antes que salvarme yo, atendí a poner a salvo diez paquetes que contenían la correspondencia grave del 
coronel Balta dejando en él solo las cartas de rutina" (Palma, 2005, I, p. 188). A pesar del triste episodio, Palma recordó por siempre su labor de corresponsal. De acuerdo a Angélica Palma: "Enorgullecíase don Ricardo de ser cumplido corresponsal, hábito adquirido, según contaba, cuando fue secretario del presidente Balta, y que le resultó de utilidad evidentísima en la tarea bibliotecaria" (Palma, 1933, p. 133).

En 1872, Palma retorna a la labor literaria. Su alegría por regresar a esta actividad y su decepción por involucrase en el campo de la política llegó a comunicárselo a su amigo ecuatoriano Juan León Mera, a quien señaló: "Apartado hoy de la política, que tantos sinsabores proporciona, he vuelto a la vida de las letras y me tiene convertido en ratón de archivo" (Palma, 2005, I, p. 107). La edición de su primera serie de Tradiciones lo convertirá en un autor de talla internacional. Varios literatos del Perú e Hispanoamérica empezarán a escribirle, elogiando su principal obra. En 1876, Palma contrae matrimonio con Cristina Román Olivier, trasladándose a vivir al balneario de Miraflores. En 1879, se produjo la guerra con Chile. Al ingresar los chilenos en Lima, Palma participó el 15 de enero de 1881 en la batalla de Miraflores. Derrotado el ejército peruano, los invasores iniciaron numerosos actos de saqueo y pillaje en las casas miraflorinas. Uno de los más afectados fue la casa del tradicionista, que fue incendiada por las hordas chilenas, perdiéndose su biblioteca personal y su valiosa correspondencia. Apesadumbrado por lo sucedido, el escritor, no dejó de colaborar con el gobierno de Piérola, llegando a convertirse en "su corresponsal y va casi día por día dándole cuenta de todos los sucesos que ocurrían en Lima y aun en otras regiones del Perú" (Vargas Ugarte, 1964, pp. 5-6). Asimismo, a manera de correspondencia, Palma fue enviando desde la Lima ocupada por el invasor una serie de crónicas cargadas de noticias, apasionamientos y diatribas en contra de aquellos que no habían sido "leales" a su líder político, Nicolás de Piérola. 
Estas crónicas de tono epistolar, publicadas en el diario panameño El Canal, que dirigía el cónsul peruano Federico Larrañaga, fueron reunidas por el historiador estadounidense C. Norman Guice y publicadas por primera vez en 1984 bajo el título de Crónicas de la guerra con Chile (1881 - 1883). Palma usó como seudónimo Hiram, que evoca al constructor del templo del rey Salomón, figura simbólica de la masonería.

En 1883, concluida la guerra, Palma fue nombrado director de la Biblioteca Nacional por el presidente Iglesias. Al asumir sus funciones inició una labor reconstructora. Ante la falta de presupuesto para la adquisición de nuevos ejemplares tuvo que desplegar una cruzada de recolección de libros en el Perú y el extranjero, por lo que fue conocido como el bibliotecario mendigo. Precisamente, aprovechando su prestigio literario en el extranjero y sus relaciones personales con altas personalidades de España e Hispanoamérica, el autor de las Tradiciones escribió a muchas personas para solicitarles su apoyo espiritual y material. De acuerdo al escritor hondureño Rafael Heliodoro Valle, "Palma escribía cartas a sus amigos hispanoamericanos como si dilapidara una fortuna". Asimismo, gracias a la información proporcionada por Augusta y Renée Palma, se supo que el tradicionista

escribía con puntualidad, sin dejar copia de muchas de esas cartas que figuran en su haber de insigne escritor, porque si pudo dar a nuestro idioma un nuevo género de expresión, un estilo que le ha dado vida perenne, como epistológrafo supo demostrar que en el principio de la palabra fue la sonrisa y que en sus mejores cartas sabía prologar la hechicería de su espíritu burlón (citado en Palma, 1949, II, p. X).

Una de las amistades con quien tuvo una intensa correspondencia epistolar, en este período, fue con la escritora argentina Juana Manuela Gorriti, impulsora en Lima de las famosas veladas 
literarias entre 1876-1877. Las cartas dirigidas por la recordada anfitriona de tertulias al peruano han sido publicadas el año 2004 bajo el titulo Gorriti, Juana Manuela. Cincuenta y tres cartas inéditas a Ricardo Palma. Fragmentos de lo íntimo. Buenos Aires-Lima, I8821891, a cargo de la investigadora argentina Gabriela Batticuore, la misma que llegó a consultar la colección de cartas manuscritas del Archivo Palma en la Biblioteca Nacional del Perú.

$\mathrm{Al}$ igual que Juana Manuela Gorriti, Palma recibió numerosas misivas de parte de otros renombrados personajes en la década de 1880 que fueron incorporadas a su colección. Llegaron a sus manos las epístolas del abogado y escritor ecuatoriano José Rafael Arizaga, el general mexicano Vicente Riva Palacio, el intelectual y político chileno Carlos Toribio Robinet, el colombiano Luis Capella Toledo, el escritor, poeta e historiador mexicano Francisco Sosa, el uruguayo Isidoro de María, el escritor argentino Rafael Pastor Obligado, conocido como el "Palma argentino", la escritora cusqueña, Clorinda Matto de Turner, Mercedes Cabello de Carbonera, el bibliotecario José Toribio Polo, el diplomático Félix Cipriano Coronel Zegarra, entre otros más.

En 1892, Palma es designado por el gobierno del Perú, como enviado oficial a los actos conmemorativos del IV Centenario del descubrimiento de América a realizarse en la ciudad de Madrid. Viajó a la magna cita acompañado por sus hijos Angélica y Ricardo. Encontrándose en la Madre Patria, el autor de las Tradiciones acudió a reuniones académicas e intelectuales. A pesar de su recargada labor, no dejo de escribir a su esposa Cristina para contarle sobre el estado de sus hijos, así como de las reuniones en la que participaba. La correspondencia de Palma con su esposa fue publicada en 1992 con el título de Cartas a Cristina de su esposo Ricardo Palma. Esta correspondencia actualmente es propiedad de la Fundación Ricardo Palma y se encuentra en la Casa Museo Ricardo Palma, en el distrito de Miraflores. 
Al regresar de España, Palma se reincorporó a sus labores en la Biblioteca Nacional. Como de costumbre volvió a la rutinaria costumbre de escribir cartas a sus amigos peruanos y extranjeros. No es casualidad que su hija Angélica Palma haya expresado en la biografía de su padre que al cumplir una década de bibliotecario su "pluma epistolar no descansaba" (Palma, 1933, p. 105). Una de esas amistades con quien tuvo activa correspondencia epistolar, tras su regreso de España fue la escritora portorriqueña, Lola Rodríguez de Tió, a quien había conocido en Cuba en 1893. En uno de sus viajes a Puerto Rico, el reconocido intelectual Luis Alberto Sánchez tuvo acceso a las cartas que envió el tradicionista a su amiga caribeña, las mismas que llegó a copiar y reproducir facsimilarmente en 1968 bajo el título de Diecisiete cartas inéditas con otras inéditas cambiadas con doña Lola Rodríguez de Tió (1894 - 1907). Hay que señalar que el propio Palma se encargó de conservar las cartas que le enviaba su amiga portorriqueña, las mismas que se encuentran en la colección personal del archivo Ricardo Palma en la BNP.

A finales del siglo XIX, Palma recibió mayor cantidad de cartas que de costumbre. Algunos eran de saludos, otras de felicitación, aunque no faltaron también las de consejo. Entre los remitentes más frecuentes del exterior, podemos señalar al bibliófilo boliviano Gabriel René Moreno, al escritor venezolano Arístides Rojas, al poeta cubano-mexicano Pedro Santacilia, Victoriano Agüeros, al escritor Luis Gonzales Obregón, uno de los hombres más eminentes de México en el campo de la Historia y de las letras, al poeta nicaragüense Rubén Darío, al historiador guatemalteco Agustín Gómez Carrillo, al editor catalán Francisco Simón Font, uno de los fundadores de la editorial Montaner y Simón. En tanto, por el lado peruano fueron habituales corresponsales Guillermo Billinghurts, Pedro Alejandrino del Solar, Celso Víctor Torres y Modesto Silva Santisteban. 
Al iniciarse el siglo XX, las cartas recibidas no cesaban. Incrementaron su colección numerosas misivas provenientes de distintos lugares del mundo. Así, le escribieron en la primera década del 900 personajes como los presidentes Eduardo López de Romaña, Manuel Candamo y José Pardo, el escritor español Rafael Altamira, el destacado intelectual español, Marcelino Menéndez y Pelayo, el presidente argentino, general Roque Sáenz Peña, la escritora colombiana Soledad Acosta de Samper, el argentino Ernesto Quesada, el editor español Manuel Maucci, el Duque de Rivas, el científico argentino Pedro Arata, entre otros.

En 1911 falleció en la capital Cristina Román, la esposa del tradicionista. Ante tan lamentable pérdida, su hija Angélica Palma se convertirá en su nueva asistente personal, encargándose de asistir a su famoso padre en "la lectura de periódicos y libros, en los que a veces indicaba subrayados o anotaciones, dictando las cartas, o escribiéndolas personalmente, las pocas veces que la salud achacosa se lo permitía y preparando la edición definitiva de las Tradiciones" (Palma, 1933, p. 148).

En 1912 Palma renuncia a la dirección de la Biblioteca Nacional trasladándose al barrio de Miraflores. Allí, en una modesta casa, pasará sus últimos años en compañía de sus hijos y nietos, lejos del bullicio de la capital. Sin embargo, por momentos el octogenario dedicará parte de sus horas

a despachar su correspondencia epistolar, a preparar la edición definitiva de las Tradiciones y a la labor reorganizadora de la Academia Peruana, correspondiente de la Española, la cual, gracias a su empeño se inauguró solemnemente en Lima en diciembre de 1917 (Palma, 1921, pp. XII-XIII).

Hasta ese lugar el escritor será visitado por sus amigos y recibirá muchas cartas de personajes del campo académico e intelectual del Perú y del extranjero. 
El 6 de octubre de 1919, Palma falleció a la edad de ochenta y seis años. Sus libros, su vasta correspondencia y sus objetos personales quedaron bajo el cuidado de sus hijos Clemente, Angélica, Ricardo, Vital, Augusta y Renée. Por deseo expreso de su padre, la hija mayor del tradicionista, Angélica, se ocupó de la edición y la difusión de las Tradiciones. Gracias a ella, salieron a la luz las selecciones: El Palma de la juventud (1921) y La Limeña (1922), así como la edición española de las Tradiciones Peruanas a cargo de la editorial Calpe (1923-1925).

En 1933, al conmemorarse el centenario del nacimiento de Ricardo Palma, Angélica publicó la biografía de su padre a cargo de la editorial argentina "Cóndor". Según Raúl Porras, Angélica, "prosiguiendo su dulce tarea evocadora, continuó buscando en los archivos familiares, en las bibliotecas y en las gavetas de lejanos y dispersos amigos la huella literaria de su padre, tratando de iluminar todos los rincones de su espacio vital" (Porras, 1949, p. IX). En ese sentido, se encargó de copiar cartas en la biblioteca de Benito Pérez Galdós en Santander (España), solicitó copias de antiguas cartas a los integrantes de la Bohemia limeña, escribió a sus amistades en México, Estados Unidos, Argentina y Chile, en demanda de fotocopias y reproducciones y fue preparando lo que vendría a ser el primer epistolario de su padre. Lamentablemente, la muerte de Angélica en 1935 interrumpió brevemente este proyecto. A pesar de ello, Augusta y Renée decidieron concluir la meta trazada por su hermana, razón que las obligó a realizar el rescate de "nuevas epístolas y de copiar los libros de correspondencia en que su padre coleccionó las cartas recibidas, escogiendo entre ellas las más interesantes y significativas" (Porras, 1949, p. X).

En 1949, en medio de gran expectativa, salió de la imprenta la primera edición del Epistolario de Ricardo Palma. Constaba de dos volúmenes. El primero, con prólogo de Raúl Porras Barrenechea, reúne 93 cartas enviadas por el tradicionista 
entre 1876 a 1919 , mientras que el segundo, con un "Juicio Literario" de Rafael Heliodoro Valle, agrupa 152 cartas remitidas a su persona entre 1881 a 1919, todas ellas provenientes de la colección epistolar Ricardo Palma.

A pesar del revuelo generado por el Epistolario en el ambiente intelectual, las hijas del tradicionista vieron propicia la oportunidad para poner ese año en venta la biblioteca y el archivo personal de su señor padre. Al enterarse de esta noticia, los altos ejecutivos de la Biblioteca Nacional, encabezados por su director Cristóbal Losada y Puga, en concordancia con su política de adquisiciones de "obras notables y autorizadas" (Losada y Puga, 1950, p. 3) lograron adquirir el 8 de abril de 1949, el valioso patrimonio bibliográfico-documental del tradicionista por la suma de 50000 soles. Efectuada la compra, Pedro Benvenutto Murrieta, director de Educación Artística y Cultural del Ministerio de Educación, nombró una Comisión compuesta por el Director de la Biblioteca Nacional, el SubDirector de Administración y Control y el Jefe de la Sección de Biblioteca y Ediciones, quienes se encargaron de la recepción, previo inventario de la biblioteca, de cartas y demás recuerdos que pertenecieron a don Ricardo Palma (Boletín de la Biblioteca Nacional, 1949, p. 203). Al llegar a la Biblioteca Nacional los libros y la correspondencia personal del escritor limeño ingresaron al Departamento de Investigaciones Bibliográficas, dirigido por entonces por el doctor Alberto Tauro del Pino. Tauro, un acucioso investigador, presentó a la dirección de la Biblioteca un catálogo de la Biblioteca Ricardo Palma, en donde figuraban varios volúmenes de su correspondencia epistolar (Tauro del Pino, 1949, pp. 205-241). Aunque inicialmente llegaron 27 volúmenes de correspondencia, estos se redujeron con la nueva catalogación a 23 volúmenes que son los siguientes: 
1. Correspondencia. 1884-1896 (356 cartas). Tomo I

2. Correspondencia. 1884-1896 (348 cartas). Tomo II

3. Correspondencia. 1884-1896 (365 cartas). Tomo III

4. Correspondencia. 1892-1896 (191 cartas).

5. Correspondencia. 1912-1914 (70 cartas). "Humo de incienso"

6. Correspondencia. 1916-1918 (104 cartas). Último tomo de correspondencia.

7. Correspondencia. 1912-1922 (77 cartas).

8. Correspondencia académica, 1897 a 1900 (138 cartas).

9. Correspondencia del siglo XX. A. B. C. D. (465 cartas). IV Tomos.

10. Correspondencia del siglo XX. R. S. T. U. V. Z. (137 cartas).

11. Correspondencia literaria. 1888-1890 (95 cartas dirigidas a D. R. Palma durante el período de 1881-1897.

12. Correspondencia literaria. 1891 (212 cartas).

13. Correspondencia literaria. $1897-99$ (342 cartas).

14. Correspondencia literaria. 1897-1900 (336 cartas).

15. Correspondencia literaria. 1900-1907 (148 cartas dirigidas a don Ricardo Palma durante los años 1898 a 1906. Índice manuscrito al comienzo.

16. Correspondencia literaria. $1901-1903$ (280 cartas).

17. Correspondencia literaria. $1901-1907$ (205 cartas).

18. Correspondencia literaria. Colombia, 1883-1890 (130 cartas).

19. Correspondencia literaria. Chile y Bolivia. 1883-1890¹.

20. Correspondencia literaria. México. 1883-1890 (130 cartas).

21. Correspondencia literaria. Perú. 1883-1890. (227 cartas).

22. Correspondencia literaria. Repúblicas del Plata. 1883-1890. (217 cartas).

23. Correspondencia. Misión en España. 1892-1893. (183 cartas).

l No sabemos cuál es el contenido de las cartas de este volumen. Solamente consignamos el dato proporcionado por Tauro del Pino (1949, p. 212). 
Finalizada la catalogación, los libros y la correspondencia de Palma fueron puestos al servicio de los investigadores. Por varios años, cientos de estudiantes y profesionales de distintas áreas acudieron a consultar esta correspondencia. A inicios de la década de 1980, el Departamento de Investigaciones Bibliográficas pasó a convertirse en la Dirección de Investigaciones Bibliográficas y Fondos Especiales. Esta nueva oficina fue encargada de la custodia y conservación de la correspondencia de Palma y fue también la encargada de la recepción de las 59 cartas de Ricardo Palma a Narciso Pedro Arata, adquiridas por la Biblioteca Nacional en una subasta londinense en 1999 (Medan, 2018, p. 4).

Precisamente, en la década de los 90, la crítica literaria argentina, Gabriela Batticuore llegó a consultar la correspondencia de Palma; lo hizo como parte de una investigación para su libro El taller de la escritora: veladas literarias de Juana Manuela Gorriti: Lima-Buenos Aires (1876-77-1892), publicado en 1999. Asimismo, logró transcribir las cartas de la recordada escritora argentina del siglo XIX, para luego publicarlas, años después, en un interesante trabajo titulado Juana Manuela Gorriti: cincuenta y tres cartas inéditas a Ricardo Palma: fragmentos de lo intimo, Buenos Aires-Lima, 1882-1891.

$\mathrm{Al}$ iniciarse el nuevo milenio, diversos investigadores siguieron consultando la correspondencia de Ricardo Palma. Dos de ellos, Osmar Gonzales y Delfina Gonzales del Riego, ocuparon parte de su tiempo para seleccionar y transcribir las cartas que redactara el ex presidente Guillermo Billinghurts para el ilustre tradicionista, tarea conjunta que dio como resultado el libro Cartas de Guillermo E. Billinghurts a Ricardo Palma (1883-1904), publicado el año 2005.

El año 2006, al inaugurarse la nueva sede de la Biblioteca Nacional, gran parte de los fondos bibliográficos y documentales 
de la avenida Abancay fueron trasladados al nuevo local de San Borja. Entre ellos se encontraban los fondos pertenecientes a la Dirección de Investigaciones Bibliográficas y Fondos Especiales y por ende la biblioteca y el archivo Palma. Hay que señalar que cuando llegó la correspondencia del tradicionista a la nueva sede, las cartas habían sido desencuadernadas por el deterioro físico del empastado de los tomos, colocadas en sobres y puestas en cajas de cartón. En los últimos años, la custodia y atención de la correspondencia de Ricardo Palma ha estado a cargo del Centro de Servicios Bibliotecarios Especializados (CSBE), pero a partir del 2018, se encuentra bajo el control de la Dirección de Protección de las Colecciones de la Biblioteca Nacional.

\section{Naturaleza de esta colección}

Forma parte de esta colección las 4144 cartas, 17 índices y 4 tarjetas dirigidas al escritor limeño por numerosas personalidades peruanas y extranjeras entre 1880 a 1919. Estas cartas provienen de personajes vinculados al campo de la política, la literatura, la historia, la academia, el derecho, el periodismo, el arte y la sociedad civil. Aunque originalmente la colección estaba conformada por la correspondencia enviada al tradicionista, esta se ha ido incrementando con la llegada de nuevas cartas escritas por la mano prodigiosa del autor de las Tradiciones Peruanas. Tal es el caso de la correspondencia de Pedro Arata, adquirida en 1999 durante la gestión de Martha Fernández.

En esta colección pueden hallarse cartas de diversos lugares; las hay de ciudades del Perú, pero también de diversas ciudades del extranjero. Algunas de las cartas nacionales provienen de Lima, Callao, Cusco, Trujillo, Arequipa, Cajamarca, Mollendo, Latacunga, Caraz, entre otros puntos; en tanto, de las provenientes del extranjero, podemos mencionar que estas 
tienen como punto de partida ciudades como Buenos Aires, Santiago de Chile, México. D.F, Bogotá, Madrid, Washington, New York, Montevideo, Barcelona, Valparaíso, Iquique, Würzburg, La Habana, Ciudad de Guatemala, Cochabamba, La Paz, Rio de Janeiro, entre otras. Las cartas provenientes del extranjero representan un ochenta por ciento del total, superando ampliamente a las cartas provenientes del Perú.

El período temporal de la correspondencia comprende los años de 1880 a 1919. La carta más antigua pertenece a un personaje de nombre Carlos, quien la escribió en Valparaíso el 8 de noviembre de 1880, mientras que la última corresponde a la autoría del escritor uruguayo-español Daniel Granada, fechada en Madrid, el 26 de setiembre de 1919. 

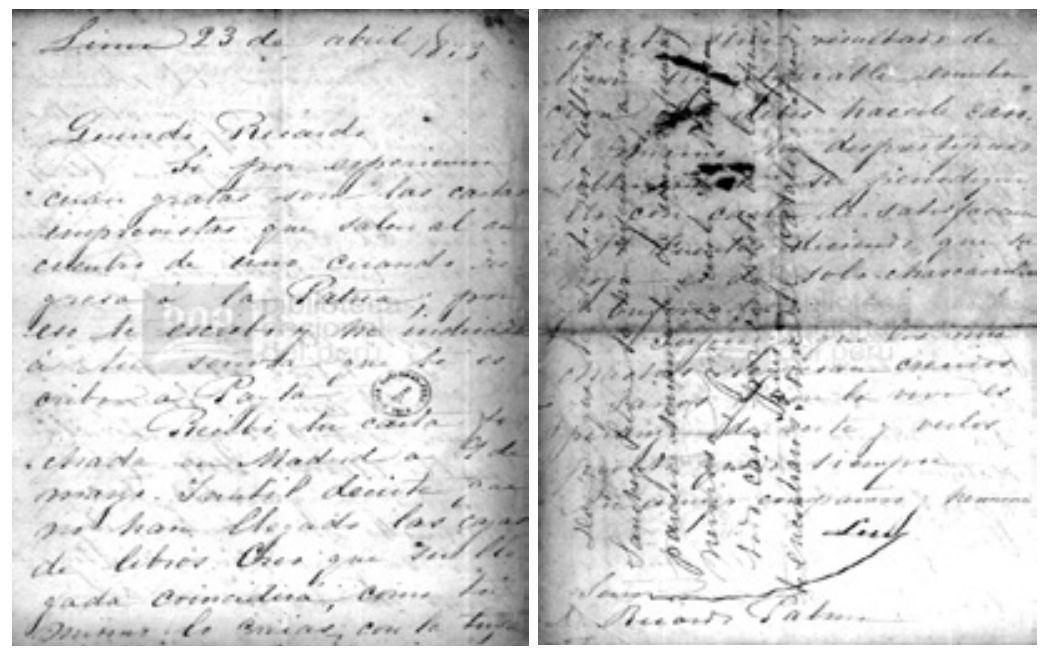

A simple vista, las cartas muestran la clara evidencia de haber sido desencuadernadas de un ejemplar empastado. Hay presencia de marcas de goma en la mayoría de ellas y presencia de hilos en las mismas. Asimismo, presentan una gran cantidad de sellos, registrados con las iniciales de la OIB. 
Carta de Luis Benjamín Cisneros a Ricardo Palma (Lima, 23 de abril de 1893).

Código: 4000003977

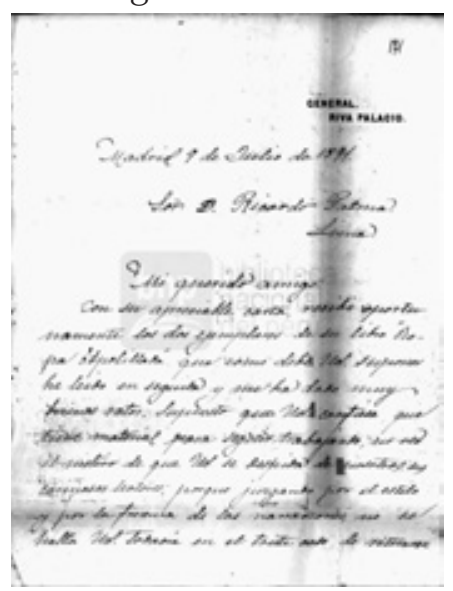

Carta del general Vicente Riva Palacio a Ricardo Palma (Madrid, 9 de julio de 1891)

Código: 4000004118

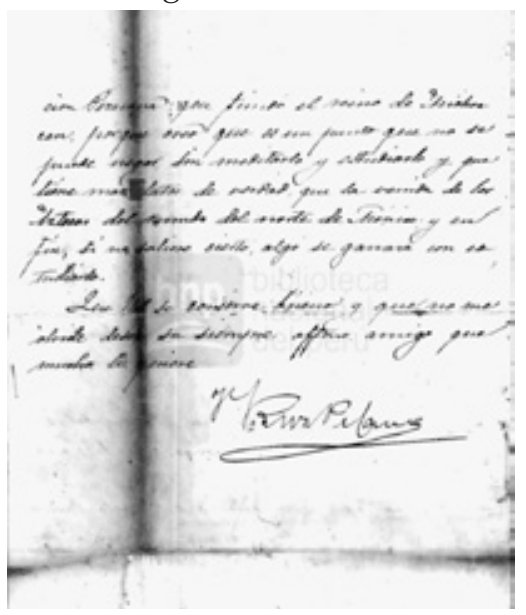




\section{Relevancia de esta colección (1880-1919)}

- Es el legado patrimonial de uno de los más reconocidos escritores peruanos de todos los tiempos. Su trascendental obra sigue concitando hasta el día de hoy un profundo interés por parte de numerosos cultores del campo literario y de las humanidades. Es labor primordial del Estado conservar la memoria histórica de sus personajes más notables. Tratándose de uno de los peruanos íconos forjadores de la peruanidad, las cartas del archivo Palma deberían de tener una mayor relevancia en la cultura nacional por su valor histórico y patrimonial.

- Es una fuente valiosa para la investigación. Esta colección constituye una de las más valiosas fuentes para el conocimiento de la historia peruana e Hispanoamericana. Por su alto contenido de información y de ideas, la vasta colección de cartas manuscritas del Archivo Palma ha sido por muchos años fuente de consulta obligada por parte de numerosos investigadores vinculados principalmente al campo de las humanidades y las ciencias sociales. De las investigaciones realizadas de estos materiales, ha surgido una impresionante cantidad de trabajos literarios, históricos, sociológicos, periodísticos, lingüísticos y culturales.

- La colección epistolar es sumamente relevante para el conocimiento de la vida y obras de numerosos personajes, ya que nos ofrece abundantes datos históricos proporcionados por los principales actores del campo político, académico, intelectual, científico y artístico del Perú y de Hispanoamérica de finales del siglo XIX y parte del XX. 


\section{Evaluación de existencias}

Por su naturaleza, se trata de una colección de cartas que fueron guardadas cuidadosamente por el autor de las Tradiciones Peruanas, desde 1880 a 1919, y que luego de su muerte pasaron a ser custodiadas por sus hijas Angélica, Augusta y Renée Palma, las mismas que se encargaron de su ordenación y catalogación hasta 1949, año en que fue vendida a la Biblioteca Nacional del Perú. Por su alto valor histórico y originalidad, la colección muestra un grado de excepcionalidad máxima que redunda en su trascendente valoración. Se considera que, como colección, se trata de un cúmulo epistolar de tipo único, imposible de comparar con otras similares en bibliotecas o en el mercado del libro antiguo.

\section{Ediciones}

Una mínima parte de la correspondencia de la Colección Ricardo Palma ha sido ya publicada por una serie de investigadores de diversas disciplinas. Hasta este momento podemos dar cuenta de algunos trabajos que han recogido cartas de esta colección:

\section{a. Edición de Cultura Antártica (1949).}

Augusta Palma se encargó de seleccionar parte de la correspondencia personal de su padre y publicarla, con la ayuda de Raúl Porras Barrenechea, en esta editorial limeña. El tomo I del Epistolario de Ricardo Palma contiene cartas ajenas a la colección, tomadas de amigos del tradicionista y de otras colecciones epistolares. El tomo II, está constituido por cartas provenientes de la colección Ricardo Palma. Apenas 152 cartas fueron seleccionadas en este volumen. 
b. Edición de Universidad San Martín de Porras (2004).

La crítica literaria argentina Gabriela Batticuore se encargó de publicar unas cartas de la escritora salteña con su colega peruano. Algunas de esas cartas publicadas fueron recogidas de la correspondencia del Archivo Ricardo Palma de la Biblioteca Nacional.

\section{c. Editorial Universitaria. Universidad Ricardo Palma (2005).}

Esta editorial publicó la correspondencia epistolar del ex presidente Guillermo Billinghurts con el escritor limeño entre 1883 y 1904. Los encargados de la selección fueron Osmar Gonzales y Delfina Gonzales del Riego quienes seleccionaron parte de la correspondencia hallada en la colección Ricardo Palma de la Biblioteca Nacional.

\section{d. Editorial de la Biblioteca Nacional del Perú (2012).}

Gracias al apoyo de la Embajada Argentina, la Biblioteca Nacional publicó las cartas intercambiadas entre el creador de las Tradiciones y el historiador y abogado argentino Adolfo Pedro Carranza, creador del Museo Histórico Nacional de su país y director del mismo durante veinticinco años. Parte de esta correspondencia proviene de la Colección Ricardo Palma de la BNP.

\section{e. Editorial Facultad de Agronomía de la Universidad de Buenos Aires (2018).}

Fue la encargada de publicar la correspondencia personal entre Ricardo Palma y Diego Arata: 1894-1910. El encargado del cuidado de la edición fue el investigador argentino Diego Medan, quien logró reunir algunas cartas digitalizadas de la Colección Ricardo Palma de la BNP. 


\section{Estado de conservación}

Se observan los efectos de la desencuadernación en los bordes de las hojas. En algunos folios se verifica oxidación y tinta corrida. Las cartas desglosadas se encuentran en sobres de cartón. La mayor parte de estas se hallan en regular estado de conservación, dentro de las limitaciones físicas naturales del soporte y las vicisitudes a lo largo del tiempo.

\section{Resultados}

- La correspondencia del Archivo Ricardo Palma constituye una valiosa e imprescindible fuente para la investigación histórica, ya que nos permite conocer parte de la vida íntima y personal de una de las figuras más representativas de la literatura peruana del siglo XIX y parte del XX, a quien le tocó vivir una época de revoluciones, modas intelectuales, crisis y caudillismos que ya es proverbial en la historia del Perú.

- La información que guarda las colecciones de cartas son de sumo valor para el conocimiento de la historia del Perú y de Hispanoamérica ya que contiene abundantes datos históricos proporcionados por los principales actores del campo político, académico, intelectual, científico y artístico del Perú y del mundo.

- Por las numerosas personalidades vinculadas al quehacer literario, las cartas del Archivo Palma contienen una valiosa información para la historia de la literatura peruana e Hispanoamericana.

- Las cartas del Archivo Ricardo Palma conservan la memoria histórica del Perú y de Latinoamérica, ya que recogen opiniones políticas, doctrinas estéticas, juicios literarios 
íntimos, indiscreciones, obsesiones y fluctuaciones de ideas entre los años 1880 a 1918.

\section{Bibliografía}

Gonzales, O. (2005). Cartas de Guillermo E. Billinghurts a Ricardo Palma (1883-1904). Lima: Universidad Ricardo Palma. Editorial Universitaria.

Gorriti, J. M. (2004). Cincuenta y tres cartas inéditas a Ricardo Palma. Fragmentos de lo íntimo. Buenos Aires - Lima, 1882 - 1891. Edición crítica. Estudio preliminar de Gabriela Batticuore. Lima: Universidad de San Martín de Porras, Escuela de Turismo.

Holguín Callo, O. (1994). Tiempos de infancia y bohemia. Ricardo Palma, 1833-1860. Lima: Pontificia Universidad Católica del Perú.

Holguín Callo, O. (2001). Páginas sobre Ricardo Palma. Lima: Universidad Ricardo Palma. Editorial Universitaria.

Losada y Puga, C. (1950). Memoria que el Director de la Biblioteca Nacional presenta al Sr. Ministro de Educación Pública: 13 de julio de 194828 de julio de 1950. Lima: Talleres Graficos P. L. Villanueva.

Medan, D. (2018). Contacto en Sudamerica: la correspondencia entre Ricardo Palma y Pedro Arata: 1894-1910 / Diego Medan; editado por Diego Medan. Ciudad Autónoma de Buenos Aires: Editorial Facultad de Agronomia. Libro digital, PDF.

Oguic, S. (2012). Correspondencia entre Ricardo Palma y Adolfo Pedro Carranza, Lima-Buenos Aires. Lima: Biblioteca Nacional del PerúEmbajada Peruana en Buenos Aires.

Palma, A. (1921). "Proemio". En: Palma, Ricardo. El Palma de la juventud. Lima: Librería Francesa y Casa Editorial E. Rosay, pp. VII-XIII. 
Palma, A. (1933). Ricardo Palma. Buenos Aires: Ediciones argentinas "Cóndor".

Palma, R. (1968). Diecisiete cartas inéditas con otras inéditas cambiadas con doña Lola Rodríguez de Tió (1894 - 1907). Con prólogo, anotaciones y un apéndice de Luis Alberto Sánchez y varias cartas facsimilares. Lima: Universidad Nacional Mayor de San Marcos.

Palma, R. (1949). Epistolario. Lima. Editorial Cultura Antártica.

Palma, Ricardo. (1992). Cartas a Cristina de su esposo Ricardo Palma. Prólogo de Estuardo Núñez. Miraflores (Lima): Municipalidad de Miraflores y Patronato de la Casa de Ricardo Palma.

Palma, Ricardo. (2005). Epistolario general. I. Lima. Universidad Ricardo Palma. Editorial Universitaria.

Porras Barrenechea, R. (1949). "Prólogo". En: Palma, R (1949). Epistolario.

Tauro del Pino, A. (1949). Museo "Ricardo Palma". Boletín de la Biblioteca Nacional, 12, pp. 202-241.

Valle, R. (1947). "El mundo americano de Palma". En: Palma, R (1949). Epistolario. Lima: Editorial Antártica. V. 